
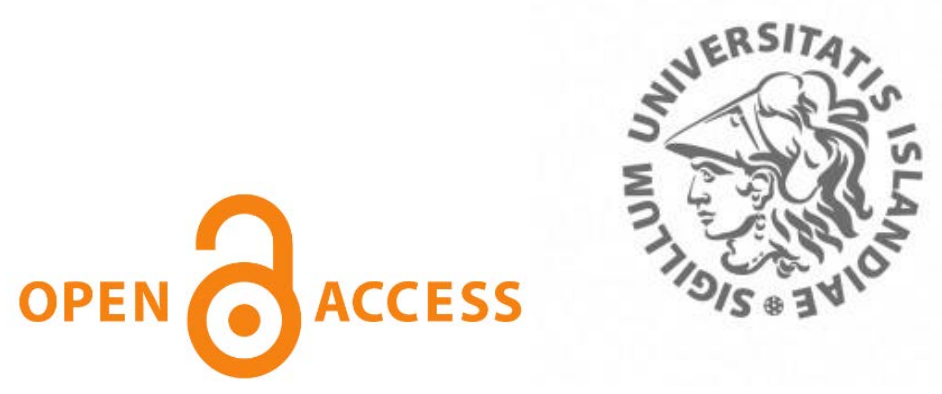

O. Opin vísindi

This is not the published version of the article / Petta er ekki útgefna útgáfa greinarinnar

Author(s)/Höf.: $\quad$ Shen, Y., Solomon, S. C., Bjarnason, I. T., \& Wolfe, C. J.

Title/Titill: Seismic evidence for a lower-mantle origin of the Iceland plume

Year/Útgáfuár: 1998

Version/Útgáfa: $\quad$ Post-print / Lokagerð höfundar

Please cite the original version:

Vinsamlega vísið til útgefnu greinarinnar:

Shen, Y., Solomon, S. C., Bjarnason, I. T., \& Wolfe, C. J. (1998).

Seismic evidence for a lower-mantle origin of the Iceland plume. Nature, 395, 62. doi:10.1038/25714

Rights/Réttur:

(C) 2018 Macmillan Publishers Limited, part of Springer Nature 


\section{Seismic evidence for a lower mantle origin of the Iceland plume}

Yang Shen ${ }^{*}$, Sean C. Solomon ${ }^{\dagger}$, Ingi Th. Bjarnason ${ }^{\ddagger}$ and Cecily J. Wolfe ${ }^{*}$

* Department of Geology and Geophysics, Woods Hole Oceanographic Institution, Woods Hole, MA 02543, USA

${ }^{\ddagger}$ Department of Terrestrial Magnetism, Carnegie Institution of Washington, 5241 Broad Branch Road, N.W., Washington DC 20015, USA

${ }^{\ddagger}$ Science Institute, University of Iceland, Reykjavik, Iceland

Iceland, one of the most thoroughly investigated hotspots ${ }^{1-3}$, is generally accepted as the manifestation of an upwelling mantle plume ${ }^{4}$, yet whether the plume originates from the lower mantle or from a convective instability at a thermal boundary layer between the upper and lower mantle near $660 \mathrm{~km}$ depth ${ }^{5,6}$ remains unconstrained. Tomographic inversions of body wave delay times show that low seismic velocities extend to at least $400 \mathrm{~km}^{\text {depth beneath central Iceland }}{ }^{7,8}$, but cannot resolve structure at greater depth. Here we report lateral variations in the depths of compressional-to-shear wave conversions at the two seismic discontinuities marking the top and bottom of the mantle transition zone beneath Iceland. The transition zone is $20 \mathrm{~km}$ thinner than in the average Earth ${ }^{9}$ beneath central and southern Iceland but is of normal thickness beneath surrounding areas, a result indicative of a hot and narrow plume originating from the lower mantle.

Observational constraints on the deep structure of plumes are sparse, with only one report of the detection of a narrow plume conduit at a depth of about $700 \mathrm{~km}$ (ref. 10). A new approach to address the question of the depth of origin of mantle plumes is to map the mantle seismic discontinuities near 410 and $660 \mathrm{~km}$ depth, features that have been identified with the transitions from the $\alpha$ to the $\beta$ phase of $(\mathrm{Mg}, \mathrm{Fe})_{2} \mathrm{SiO}_{4}$ and from $\gamma-(\mathrm{Mg}, \mathrm{Fe})_{2} \mathrm{SiO}_{4}$ to perovskite plus 
magnesiowustite ${ }^{11}$, respectively. The depths to the $410-$ and $660-\mathrm{km}$ discontinuities respectively increase and decrease with increasing temperature and thus provide information on lateral temperature variations and associated mantle circulation patterns. As sketched in Figure 1, lateral variations in the discontinuity depths can be diagnostic of the depth of origin of mantle plumes.

The data used in this study are receiver functions ${ }^{12}$ derived from body wave records of teleseismic earthquakes from the broadband ICEMELT seismic network ${ }^{13}$ and the permanent Global Seismographic Network (GSN) station BORG on Iceland (Fig. 2). The calculation of receiver functions follows procedures previously described ${ }^{14}$.

To image lateral variations in seismic discontinuities, we use geographic binning of receiver functions ${ }^{15}$. At a given binning depth beneath Iceland and the surrounding area, we divide the horizontal plane into overlapping square patches (200-by-200 km², Fig. 2), comparable in dimension to the Fresnel zone of a $P 660 s$ phase ( $P d s$ denotes a $P$-to- $S$ conversion at depth $d$ ) of frequency $0.1-0.3 \mathrm{~Hz}$ at the conversion depth. Each patch overlaps two thirds of its area with adjacent patches. For every $10-\mathrm{km}$ increment in binning depth from the surface to $1200 \mathrm{~km}$, receiver functions having $P d s$ paths that pierce the same patch are gathered (Fig. 2), corrected for moveout to a reference ray parameter of $0.0573 \mathrm{~s} / \mathrm{km}$ (ref. 14), and stacked using an $n$-th root method $^{16}(n=2)$ in the time window corresponding to the given binning depth interval.

The stacked receiver functions clearly reveal arrivals corresponding to the 410 - and $660-\mathrm{km}$ discontinuities (Fig. 3). There is no evidence for a coherent $P$-to- $S$ conversion from near $520 \mathrm{~km}$ depth $^{17}$. North of Iceland, variations in P410s and P660s times are positively correlated and comparable in magnitude (Fig. 3b). Such a positive correlation reflects velocity heterogeneities shallower than the $410-\mathrm{km}$ discontinuity because of the nearly identical paths of $P 660 \mathrm{~s}$ and $P 410 \mathrm{~s}$ over that depth interval. P660s-P410s differential times, which provide information on the thickness of the transition zone, are not sensitive to heterogeneities shallower than the $410-\mathrm{km}$ discontinuity and are similar to that predicted by the iasp 91 global model ${ }^{9}$ (Fig. 3b). The positive correlation between P410s and P660s times breaks down beneath central and southern Iceland (Figs. 3c and 3d), where observed P660s-P410s differential times are less than that predicted by 
iasp 91 by as much as $2.2 \mathrm{~s}$. We applied corrections for velocity heterogeneity in the upper $400 \mathrm{~km}$ using $P$ and $S$ tomographic models ${ }^{8}$ and for $P d s$ shear-wave splitting using the results from $S K S$ splitting analysis ${ }^{18}$. Station terms in the tomographic models ${ }^{8}$ are incorporated, under the assumption that they reflect a uniform contribution from the upper $100 \mathrm{~km}$. These corrections do not change the general pattern of differential times and only partially remove the effects of velocity heterogeneity (Fig. 3b), because the tomographic inversions underestimate the magnitude of the velocity anomalies ${ }^{8}$. Stacks of randomly selected receiver functions (see Suplementary Information) show significantly less coherence for the converted phases than the correctly binned stacks, indicating that the observed discontinuity structure is real.

The mantle transition zone thickness beneath central and southern Iceland implied by the P660s-P410s differential times is less than beneath surrounding areas by about $20 \mathrm{~km}$. The location and east-west dimension $(400 \mathrm{~km})$ of the region of the thinner and therefore hotter than normal transition zone (Fig. 4) are generally consistent with the location and diameter of the lowvelocity anomalies at $300 \mathrm{~km}$ depth imaged in the tomographic models ${ }^{8}$. The mantle transition zone thickness beneath the areas surrounding central and southern Iceland is comparable to that of the iasp 91 model $^{9}$. Observations of long-period $S S$ precursors ${ }^{17}$ indicate that the mantle transition zone in most oceanic areas is unlikely to be significantly thicker than in iasp 91 . This inference provides a basis for a discussion of the depth of origin of the Iceland plume.

The combination of a thinner transition zone beneath central and southern Iceland and a normal transition zone beneath surrounding areas is contrary to models in which the plume originates from an instability in a boundary layer at the base of the upper mantle as a result of regional heating from below ${ }^{19,20}$ (Fig. 1c). Numerical and experimental studies have shown that the horizontal extent of the portion of the boundary layer supplying the thermal and mass flux at a plume is much greater than the diameter of the plume conduit ${ }^{21}$; in particular, the area of a conductive boundary layer 50$100 \mathrm{~km}$ thick supplying the plume would have to be $1000-2000 \mathrm{~km}$ in horizontal extent to match the excess heat flux at Iceland ${ }^{22}$. A broad boundary-layer instability (Fig. 1c) having an excess temperature of $150-200 \mathrm{~K}$ (ref. 2) would reduce the depth of the $660-\mathrm{km}$ discontinuity and the 
transition zone thickness by $8-10 \mathrm{~km}(0.8-1.0 \mathrm{~s}$ differential P660s-P410s time) over a broad region, inconsistent with the normal transition zone thickness observed beneath the areas surrounding central and southern Iceland.

The thinner transition zone appears to be circular within the mapped area and does not follow the geometry of the Mid-Atlantic Ridge (Fig. 4). This pattern suggests that a thinner transition zone is not a general feature of mid-ocean ridges. In support of this observation, receiver functions from seafloor seismic stations on the southern East Pacific Rise ${ }^{23}$ show that the average thickness of the underlying mantle transition zone is comparable to iasp91. Precursors to $S S$ waves reflected beneath the northern East Pacific Rise show no significant difference in the transition zone discontinuity depths beneath seafloor younger than $10 \mathrm{Ma}$ and those beneath older seafloor $^{24}$. Although the transition zone thickness beneath the area southeast of Iceland remains to be mapped and we cannot fully rule out the possibility of a larger, regional anomaly, the fact that the thinner transition zone underlies the column of low seismic velocities in the tomographic models ${ }^{8}$ and does not follow the ridge geometry suggests that the thinner transition zone is associated with the Iceland mantle plume.

Several lines of evidence, including tomographic images of subducting slabs penetrating the lower mantle in some areas ${ }^{25}$ and the localized depression of the $660-\mathrm{km}$ discontinuity beneath subduction zones $^{26,27}$, argue against a global thermal boundary layer above the $660-\mathrm{km}$ discontinuity. Under two-layer mantle convection scenarios, upwelling beneath spreading ridges would entrain anomalously hot material from such a boundary layer ${ }^{28}$ and result in a deeper than normal $410-\mathrm{km}$ discontinuity and a thinner than normal transition zone in the upwelling column, contrary to a normal mantle transition zone thickness beneath most ridges. For strongly-layered mantle convection models in which the depth of the $660-\mathrm{km}$ discontinuity is nearly constant $\mathrm{t}^{5,19}$ (Fig. 1b), the low seismic velocities in the upper $400 \mathrm{~km}$ (ref. 8) and the thin and anonamously hot mantle transition zone beneath central and southern Iceland would result in greater delays to P660s arrivals in those areas, contrary to observations that P660s times beneath central and southern Iceland are less than beneath adjacent areas, except near the eastern and northern edges of the 
mapped region (Fig. 3c and 3d) where relatively faster average upper mantle velocities along the paths of the converted phases appear to be present. Although the imaged discontinuity topography is affected by no correction or an undercorrection for velocity heterogeneity, corrections using seismic models with a narrower mantle plume and a larger velocity anomaly ${ }^{8}$ and including delays expected from higher than normal temperatures of a plume in the transition zone beneath central and southern Iceland (about $0.2 \mathrm{~s}$ per $100 \mathrm{~K}$ excess temperature) would only further enhance the relief of the shallower apparent depth of the $660-\mathrm{km}$ discontinuity and reduce the transition zone thickness beneath central and southern Iceland.

Our observations are therefore most consistent with a lower mantle origin for the Iceland plume (Fig. 1a). The variation in the depth to the $660-\mathrm{km}$ discontinuity beneath Iceland is also consistent with our premise that the observed discontinuity corresponds to a mineralogical phase boundary, rather than a chemical boundary, since a chemically stratified boundary between the upper and lower mantle would be deflected by as much as several hundred kilometers by an upwelling plume $^{19,20}$ from the lower mantle. For Clapeyron slopes of 2.9 and $-2.1 \mathrm{MPa} / \mathrm{K}$ for the 410 - and $660-\mathrm{km}$ discontinuities ${ }^{29}$, the $20-\mathrm{km}$ lesser than normal transition zone thickness beneath central and southern Iceland is equivalent to an excess temperature of $150 \mathrm{~K}$, a result in good agreement with estimates of the thermal anomaly at the depth of melt generation $(<200 \mathrm{~km})^{2}$. The inferred excess temperature $(150 \mathrm{~K})$ and radius of the plume $(200 \mathrm{~km})$ should be regarded as lower and upper bounds, respectively, because the finite sizes of both the Fresnel zones of the converted phases and the patches used for stacking tend to smooth lateral variations in discontinuity depths (see Supplementary Information). These values nonetheless provide strong support for models of a hot and narrow plume penetrating the mantle transition zone beneath Iceland and against models in which the plume is broader (radius $>300 \mathrm{~km}$ ) and of lesser excess temperature $(\Delta \mathrm{T} \approx 70 \mathrm{~K})^{3}$.

1. Schilling, J. G. Iceland mantle plume: Geochemical study of Reykjanes Ridge. Nature 242, 565-571 (1973). 
2. White, R. S., Bown, J. W. \& Smallwood, J. R. The temperature of the Iceland plume and the origin of outward-propagating V-shaped ridges. J. Geol. Soc. London 152, 1039-1045 (1995).

3. Ribe, N. M., Christensen, U. R. \& Theissing J. The dynamics of plume-ridge interaction, 1: Ridge-centered plumes. Earth Planet. Sci. Lett. 134, 155-168 (1995).

4. Morgan, W. J. Convection plumes in the lower mantle. Nature 230, 42-43 (1971).

5. Richter, F. M. \& McKenzie, D. P. On some consequences and possible causes of layered mantle convection. J. Geophys. Res. 86, 6133-6142 (1981).

6. Anderson, D. L. Hotspots, basalts and the evolution of the mantle. Science 213, 82-89 (1981).

7. Tryggvason, K., Husebye, E. S. \& Stefánsson, R. Seismic image of the hypothesized Icelandic hot spot. Tectonophysics 100, 94-118 (1983).

8. Wolfe, C. J., Bjarnason, I. Th., VanDecar, J. C. \& Solomon, S. C. Seismic structure of the Iceland mantle plume. Nature 385, 245-247 (1997).

9. Kennett, B. L. N. \& Engdahl, E. R. Travel times for global earthquake location and phase identification. Geophys. J. Int. 105, 429-466 (1991).

10. Nataf, H.-C. \& VanDecar, J. Seismological detection of a mantle plume? Nature 364, 115$120(1993)$.

11. Liu, L.-G. in The Earth: Its Origin, Structure and Evolution (ed McElhinny, M.W.) 177-202 (Academic, San Diego, Calif., 1979).

12. Langston, C. A. Structure under Mount Rainier, Washington, inferred from teleseismic body waves. J. Geophys. Res. 84, 4749-4762 (1979).

13. Bjarnason, I. Th., Wolfe, C. J., Solomon, S. C. \& Gudmundson, G. Initial results from the ICEMELT experiment: Body-wave delay times and shear-wave splitting across Iceland. Geophys. Res. Lett. 23, 459-462 (1996); Correction. Geophys. Res. Lett. 23, 903 (1996). 
14. Shen, Y., Solomon, S. C., Bjarnason, I. Th. \& Purdy, G. M. Hot mantle transition zone beneath Iceland and the adjacent Mid-Atlantic Ridge inferred from P-to-S conversions at the 410- and 660-km discontinuities. Geophys. Res. Lett. 23, 3527-3530 (1996).

15. Dueker, K. G. \& Sheehan, A. F. Mantle discontinuity structure from midpoint stacks of converted $\mathrm{P}$ to $\mathrm{S}$ waves across the Yellowstone hotspot track. J. Geophys. Res. 102, 83138327 (1997).

16. Kanasewich, E.R., Hemmings, C.D. \& Alpaslan, T. N-th root stack nonlinear multichannel filter. Geophysics 38, 327-338 (1973).

17. Shearer, P. M. Transition zone gradients and the 520-km discontinuity. J. Geophys. Res. 101, 3053-3066 (1996).

18. Bjarnason, I. Th., Silver, P. G. \& Solomon, S. C. Teleseismic shear wave splitting near the Iceland hotspot: Results from ICEMELT (abstract). Eos Trans. AGU 78, S322 (1997).

19. Nakakuki, T., Sato, H. \& Fujimoto, H. Interaction of the upwelling plume with the phase and chemical boundary at the $670 \mathrm{~km}$ discontinuity: Effects of temperature-dependent viscosity. Earth Planet. Sci. Lett. 121, 369-384 (1994).

20. Kellogg, L. H. Interactions of plumes with a compositional boundary at $670 \mathrm{~km}$. Geophys. Res. Lett. 18, 865-868 (1991).

21. Olson, P., Schubert, G., Anderson, C. \& Goldman, P. Plume formation and lithosphere erosion: A comparison of laboratory and numerical experiments. J. Geophys. Res. 93, 15,065-15,084 (1988).

22. Sleep, N. H. Hotspots and mantle plumes: Some phenomenology. J. Geophys. Res. 95, 6715-6736 (1990).

23. Shen, Y., Sheehan, A. F., Dueker, K. G., de Groot-Hedlin, C. \& Gilbert H. Mantle discontinuity structure beneath the southern East Pacific Rise from P-to-S converted phases. Submitted to Science, (1998).

24. Lee, D.-K. \& Grand, S. P. Depths of the upper mantle discontinuities beneath the East Pacific Rise. Geophys. Res. Lett. 23, 3369-3372 (1996). 
25. van der Hilst, R. D., Widiyantoro, S. \& Engdahl, E. R. Evidence for deep mantle circulation from global tomography. Nature 386, 578-584 (1997).

26. Wicks, C. W. \& Richards, M. A. A detailed map of the $660-\mathrm{km}$ discontinuity beneath the IzuBonin subduction zone. Science 261, 1424-1427 (1993).

27. Niu, F. \& Kawakatsu, H. Direct evidence for the undulation of the $660-\mathrm{km}$ discontinuity beneath Tonga: Comparison of Japan and California array data. Geophys. Res. Lett. 22, 531534 (1995).

28. Zhong, S. \& Gurnis M. Role of plates and temperature-dependent viscosity in phase change dynamics. J. Geophys. Res. 99, 15,903-15,917 (1994).

29. Bina, C. R. \& Helffrich, G. Phase transition Clapeyron slopes and transition zone seismic discontinuity topography. J. Geophys. Res. 99, 15,853-15-860 (1994).

30. Efron, B. \& Gong, G. A leisure look at the bootstrap, the jackknife, and cross-validation. Amer. Stat. 37, 36-48 (1983).

\section{Supplementary Information}

Acknowledgments: We thank Bjorn Bjarnason, Birgir Bjarnason, B. Brandsdóttir, H. Brynjlfósson, K. Egilsson, G. Gudmundson, E. Hannesson, T. Hardarson, L. Helgason, B. Ingimundarson, H. Jónsson, E. Kjartansson, A. Kuehnel, R. Kuehnel, P. Sigurdsson, R. Thrudmarsson, and the staff of the National Electric Company of Iceland (Landsvirkjun) for assistance with field operations; the IRIS-DMS for making available data from GSN station BORG; G. M. Purdy, D. W. Forsyth, R. S. Detrick, and J. A. Collins for encouragement and advice in the early stages of this work; S. van der Lee for providing software; D. E. James, E. M. Parmentier, I. S. Sacks, and P. G. Silver for helpful discussions; and G. Helffrich, P. van Keken, and an anonymous reviewer for constructive reviews. This work was supported by the US NSF. 
Correspondence should be addressed to Y.S. (e-mail: yshen@whoi.edu).

Figure 1 Variations in the depths of the 410 - and $660-\mathrm{km}$ phase boundaries can distinguish three genêralized, end-member scenarios for mantle plumes, here depicted schematically. Horizontal dashed lines denote 410 and $660 \mathrm{~km}$ depth. The seismic discontinuities associated with the phase changes are shown as thick lines. The shaded regions represent hotter-than-normal mantle material associated with plumes; the stippled regions represent hot lower mantle material. (a) Under the scenario in which a plume originates from the lower mantle ${ }^{4}$, the depths to the $410-$ and $660-\mathrm{km}$ discontinuities are deeper and shallower than normal, respectively, but only in the immediate vicinity of the plume conduit. (b) In one type of strongly-layered mantle convection scenario, plumes arise from instabilities in a global thermal boundary layer at the base of the upper mantle marked by the $660-\mathrm{km}$ phase boundary, and lateral variations in temperatures at the base of the boundary layer are generally less than the excess temperature of the plumes ${ }^{5,19}$. The depth to the $660-\mathrm{km}$ discontinuity is thus nearly constant and, by definition, that of the average Earth ${ }^{9}$. The $410-\mathrm{km}$ discontinuity is deeper than normal in the vicinity of the plume conduit. (c) In another type of layered-mantle convection scenario, plumes arise from regions of the boundary layer at the base of the upper mantle that are heated by the underlying lower mantle ${ }^{20}$. The horizontal extent of the portion of the boundary layer supplying the plume is much greater than the diameter of the plume conduit, reducing the depth of the $660-\mathrm{km}$ discontinuity, and thus the thickness of the mantle transition zone, over a broad region.

Figure 2 Locations of the piercing points of $P 660 \mathrm{~s}$ ray paths at the $660-\mathrm{km}$ discontinuity (crosses) and the P660s ray paths (lines) from the central patch (gray square) to the ICEMELT seismic stations and the GSN station BORG (dots). The Icelandic coast and the Reykjanes and Kolbeinsey ridges are represented by regional bathymetry at $1-\mathrm{km}$ contours. A total of 1560 pairs of radial and transverse receiver functions sample the discontinuity. 
Figure 3 Images of $P 410 s$ and P660s in stacked receiver functions. P660s-P410s differential times indicate an anomalously thin transition zone beneath central and southern Iceland. (a) Locations of the profiles of receiver functions stacks. (b) The left-hand and middle panels display relative amplitudes of receiver function stacks along an east-west profile north of Iceland. Red and yellow colors respresent positive and relatively higher amplitude arrivals. Note that the $n$-th root stacking ${ }^{16}$ amplifies weak signals in noisy data, but does not preserve amplitudes and waveforms. The vertical axis is the time after the compressional wave $(P)$ arrival. Receiver functions are uncorrected (left panel) or have been corrected (middle panel) for the splitting of the converted phases and velocity heterogeneity in the upper $400 \mathrm{~km}$. P660s-P410s differential times (right panel) are similar to that predicted for the iasp91 global model $^{9}(23.9 \mathrm{~s}$, blue horizontal line) for both corrected (red circles) and uncorrected (black circles) receiver functions. The P410s and P660s times, the differential times, and their $1-\sigma$ errors are estimated using a bootstrap method ${ }^{30}$. The relative amplitudes of identified $P 410 \mathrm{~s}$ and $P 660 \mathrm{~s}$ phases are greater than twice the levels of similarly processed and stacked records of noise immediately prior to the corresponding $P$ arrivals. A 1 -s change in differential time is equivalent to about a $10-\mathrm{km}$ change in the transition zone thickness. (c) An east-west profile through central Iceland. (d) A north-south profile through central Iceland.

Figure 4 Map view of differences between the observed P660s-P410s differential times and the value predicted for the iasp 91 model $^{9}$ underscores the localized nature of the anomaly. Receiver functions have not been corrected for shear-wave splitting or velocity heterogeneity in the upper $400 \mathrm{~km}$; such corrections do not change the general pattern of differential times (Figure 3 and see Supplementary Information). Red and yellow colors indicate significantly smaller differential times (thinner mantle transition zone) than in iasp91, while blue colors denote normal or somewhat greater differential times (normal or slightly thicker mantle transition zone). The images have been smoothed by a two-dimensional, 5-point moving average. 

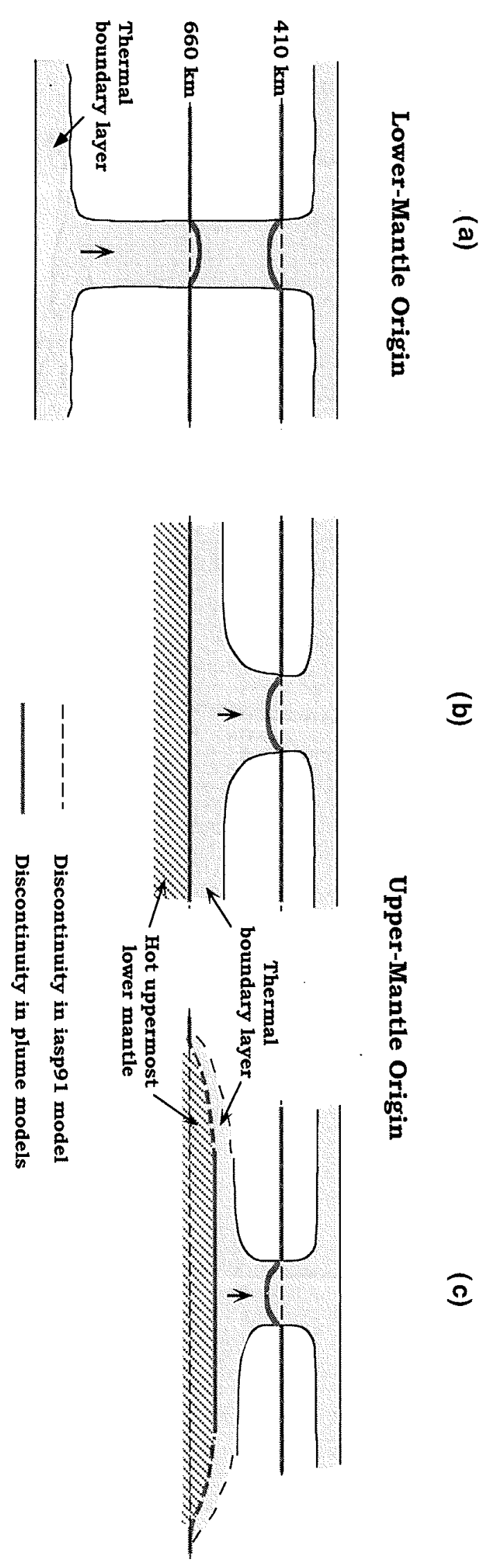


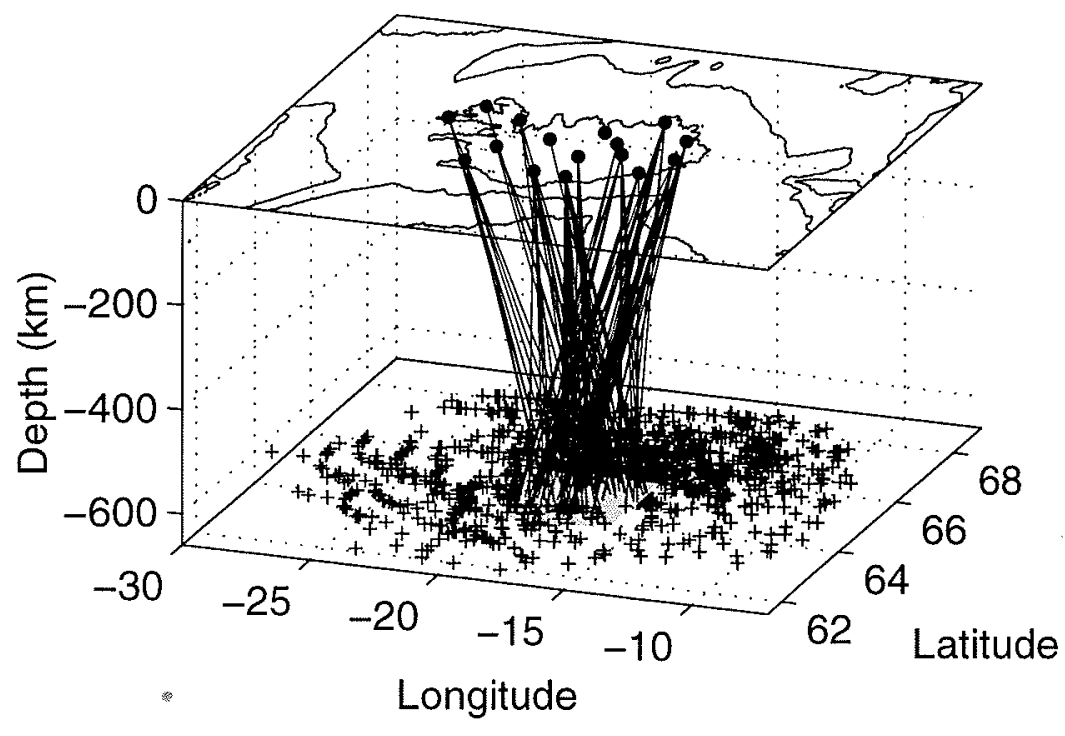

Fig 2 
b

No correction

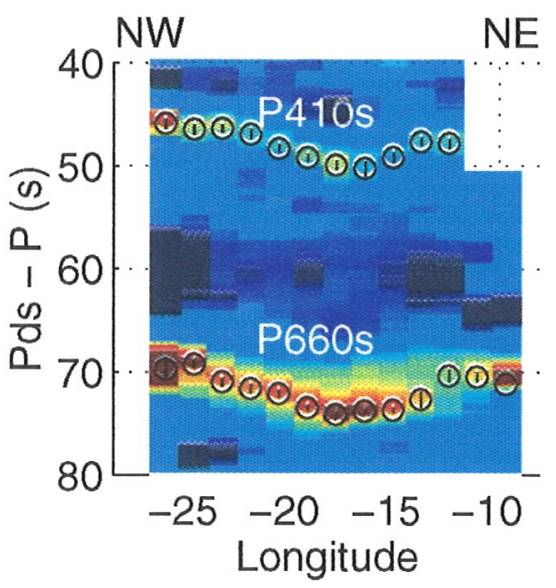

c

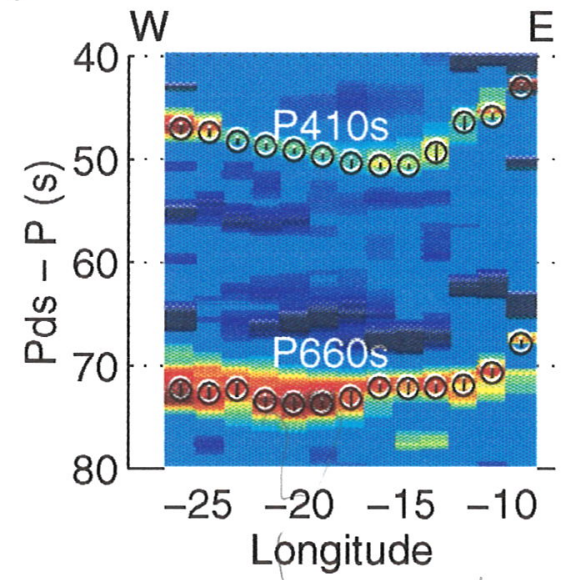

d

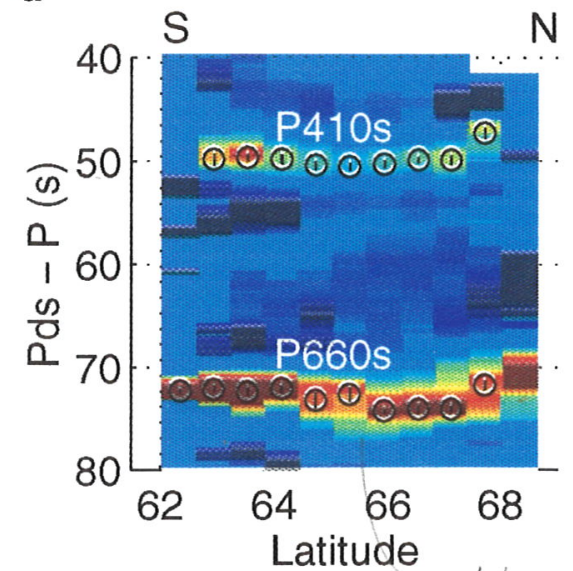

Corrected for upper $400 \mathrm{~km}$
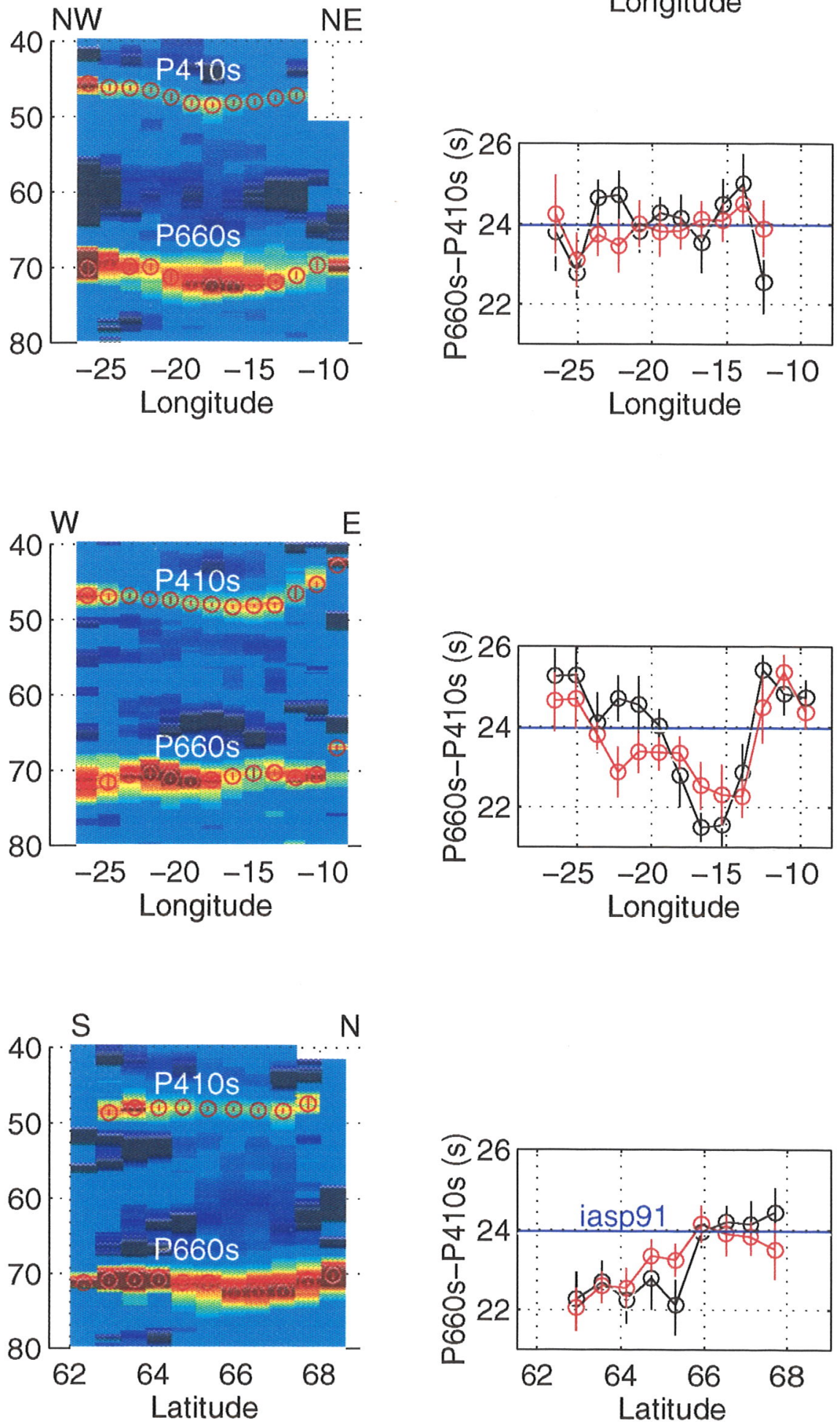

N

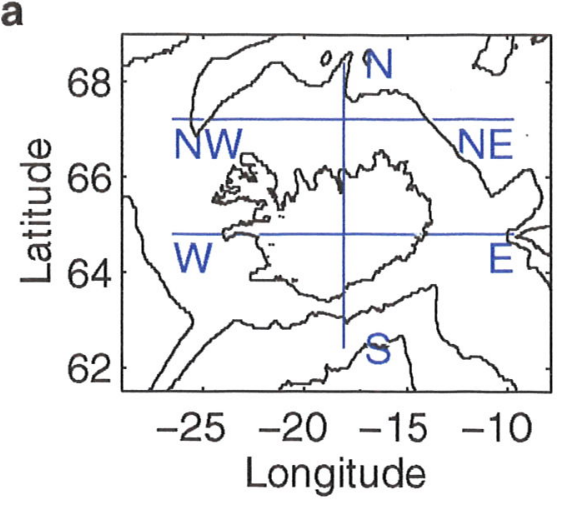


P660s-P410s (s, iasp91-observed)

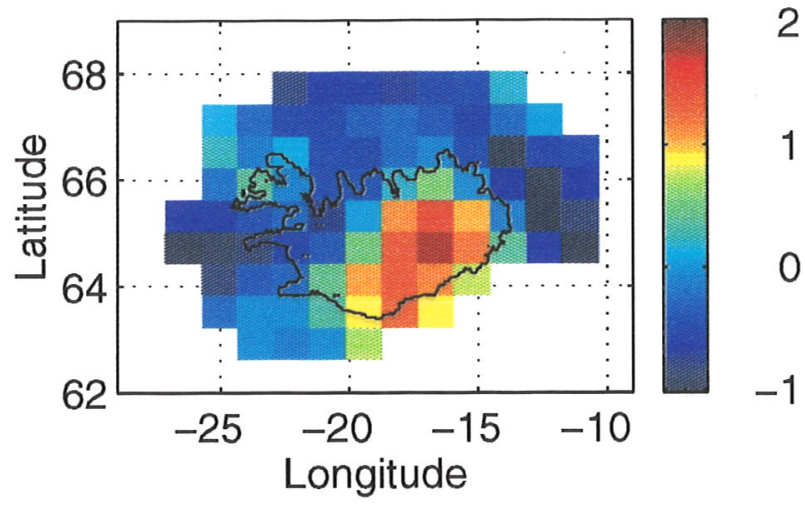

Fig 4 


\section{Supplementary Information}

Figure S1 Images of $P 410 s$ and P660s and P660s-P410s differential times in stacked receiver functions randomly selected from a pool of 1560 receiver functions. Each bin has the same number of receiver functions as in Figure 3. (a) Locations of the profiles of receiver functions stacks. (b) The left panel displays relative amplitudes of receiver function stacks along an eastwest profile north of Iceland. Red and yellow colors respresent positive and relatively higher amplitude arrivals. Receiver functions have not been corrected for velocity heterogeneity or splitting of the converted phases. The P410s and P660s arrivals are indicated. Note that lateral coherence of the converted phases is significantly less than in the correctly binned stacks (Figure 3), indicating that the observed discontinuity structure in Figures 3 and 4 is real. The P660sP410s differential times (right panel) are compared to that predicted for the iasp 91 global model ${ }^{9}$ (23.9 s, blue horizontal line). The P410s andP660s times, the differential times, and their $1-\sigma$ errors are estimated using a bootstrap method ${ }^{30}$. The amplitudes of identified P410s and P660s phases are greater than twice the levels of similarly processed and stacked records of noise immediately prior to the corresponding $P$ arrivals. A 1 -s change in differential time is equivalent to about a 10-km change in the transition zone thickness. (c) An east-west profile through central Iceland. (d) A north-south profile through central Iceland.

Figure S2 Synthetic P660s waveforms for a flat $660-\mathrm{km}$ discontinuity and a dome-shaped elevation of the $660-\mathrm{km}$ discontinuity. (a) P660s ray paths from the $660-\mathrm{km}$ discontinuity to a two-dimensional array of receivers. The boundary of the dome-shaped elevation of the $660-\mathrm{km}$ discontinuity, which has a radius of $150 \mathrm{~km}$ and a height of $15 \mathrm{~km}$, is outlined as a red circle. The $\mathrm{x}$-axis is the distance from an earthquake source to the piercing points of $P 660 \mathrm{~s}$ ray paths on the $660-\mathrm{km}$ discontinuity along the line connecting the source and the center of the dome. The y-axis is the distance from that line. (b) The dome-shaped elevation of the $660-\mathrm{km}$ discontinuity (red 
curve) and the retrieved topography from individual (red crosses) and binned (blue curve) synthetic P660s waveforms along the line from the source to the center of the dome. The geographic binning follows the same procedures as for the actual data. We can potentially detect the domeshaped elevation of the $660-\mathrm{km}$ discontinuity over about a $400-\mathrm{km}$-diameter region and retrieve from synthetic waveforms about $65 \%$ of the maximum amplitude of the topography. (c) Synthetic P660s waveforms at receivers on the line connecting the source to the center of the dome. The waveforms are calculated using a Kirchhoff-Helmholtz integration over the wave fields at the 660$\mathrm{km}$ discontinuity interface ${ }^{\mathrm{s}}$. The dominant frequency of the synthetic P660s is $0.1 \mathrm{~Hz}$, at the low end of the frequency range in ICEMELT receiver functions $(0.1-0.3 \mathrm{~Hz})$.

Figure S3 Map view of differences between the observed P660s-P410s differential times and the value predicted for the iasp 91 model $^{9}$ underscores the localized nature of the anomaly. Receiver functions have been corrected for shear-wave splitting and velocity heterogeneity in the upper 400 km. Red and yellow colors indicate significantly smaller differential times (thinner mantle transition zone) than in iasp91, while blue colors denote normal or somewhat greater differential times (normal or slightly thicker mantle transition zone). The images have been smoothed by a two-dimensional, 5-point moving average. While the corrections result in some shift in the magnitude and location of the P660s-P410s anomaly (also see Figures 3 and 4), there remains a significantly thinner transition zone beneath central and southern Iceland.

S1. van der Lee, S., Paulssen, H. \& Nolet, G. Variability of P660s phases as a consequence of topography of the $660 \mathrm{~km}$ discontinuity. Phys. Earth Planet. Inter. 86, 147-164 (1994). 
Random gathers

b

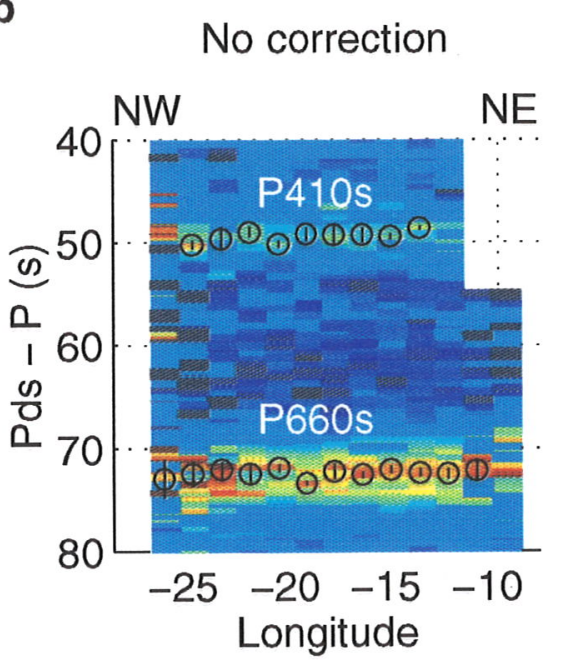

c

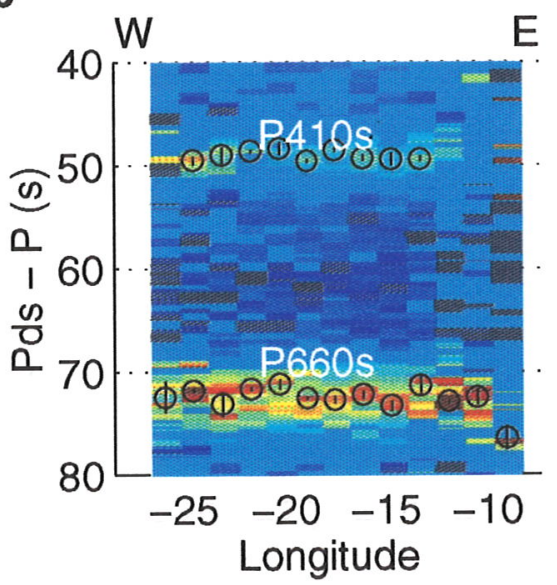

d

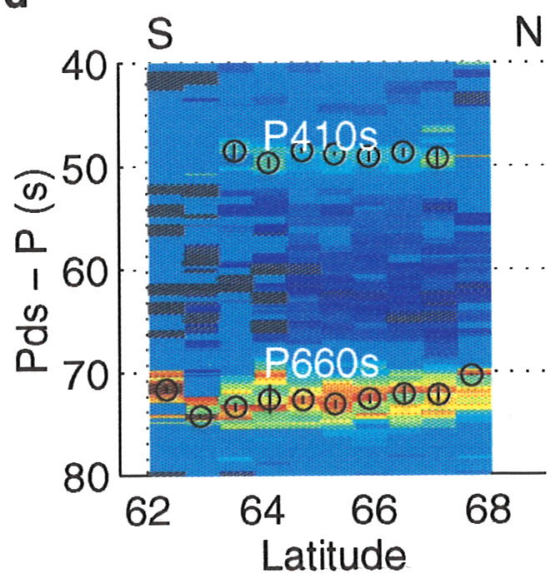

a

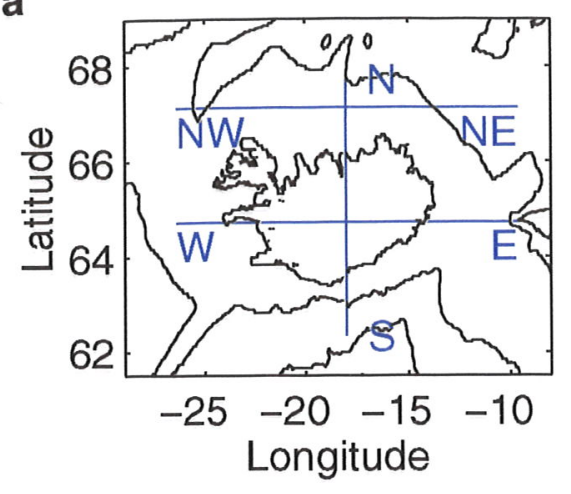

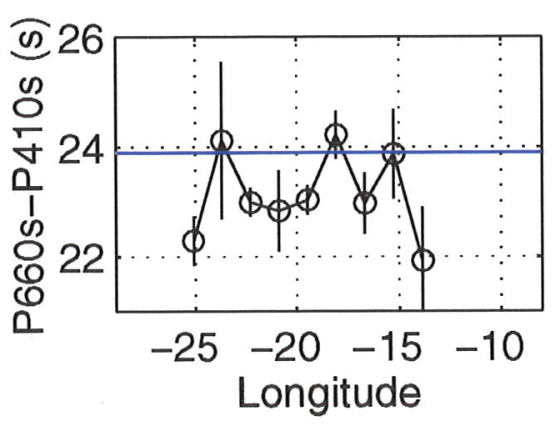

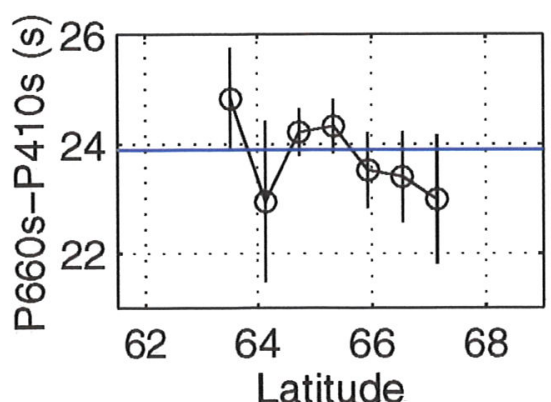


a

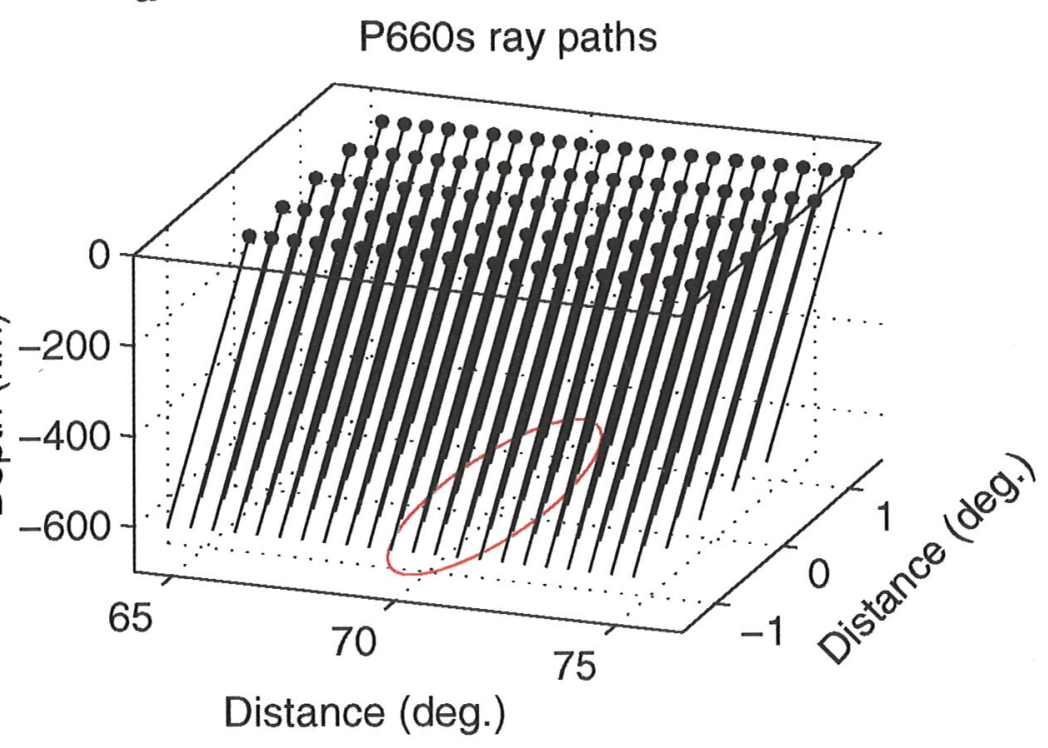

b

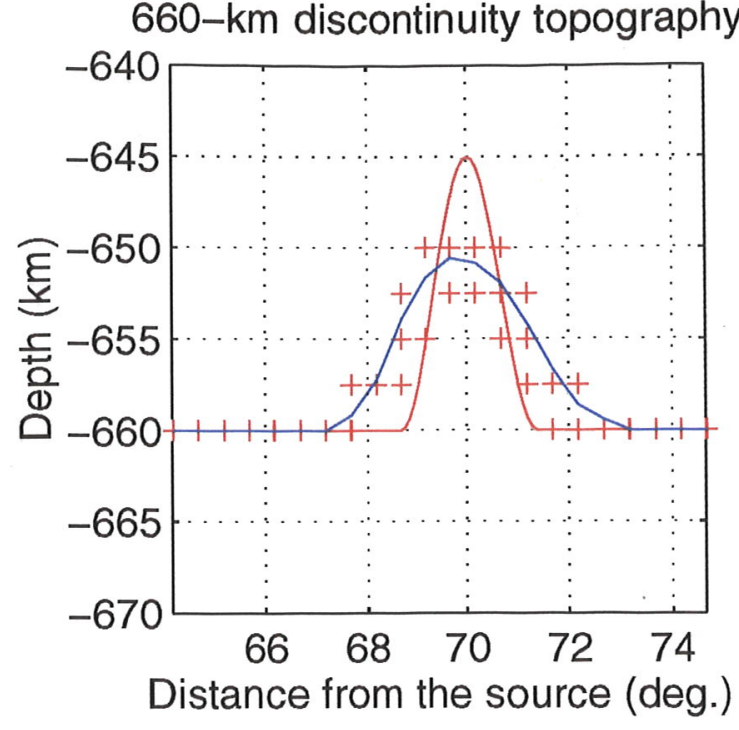

C

Synthetic P660s: Flat (black) vs domed (red) discontinuity

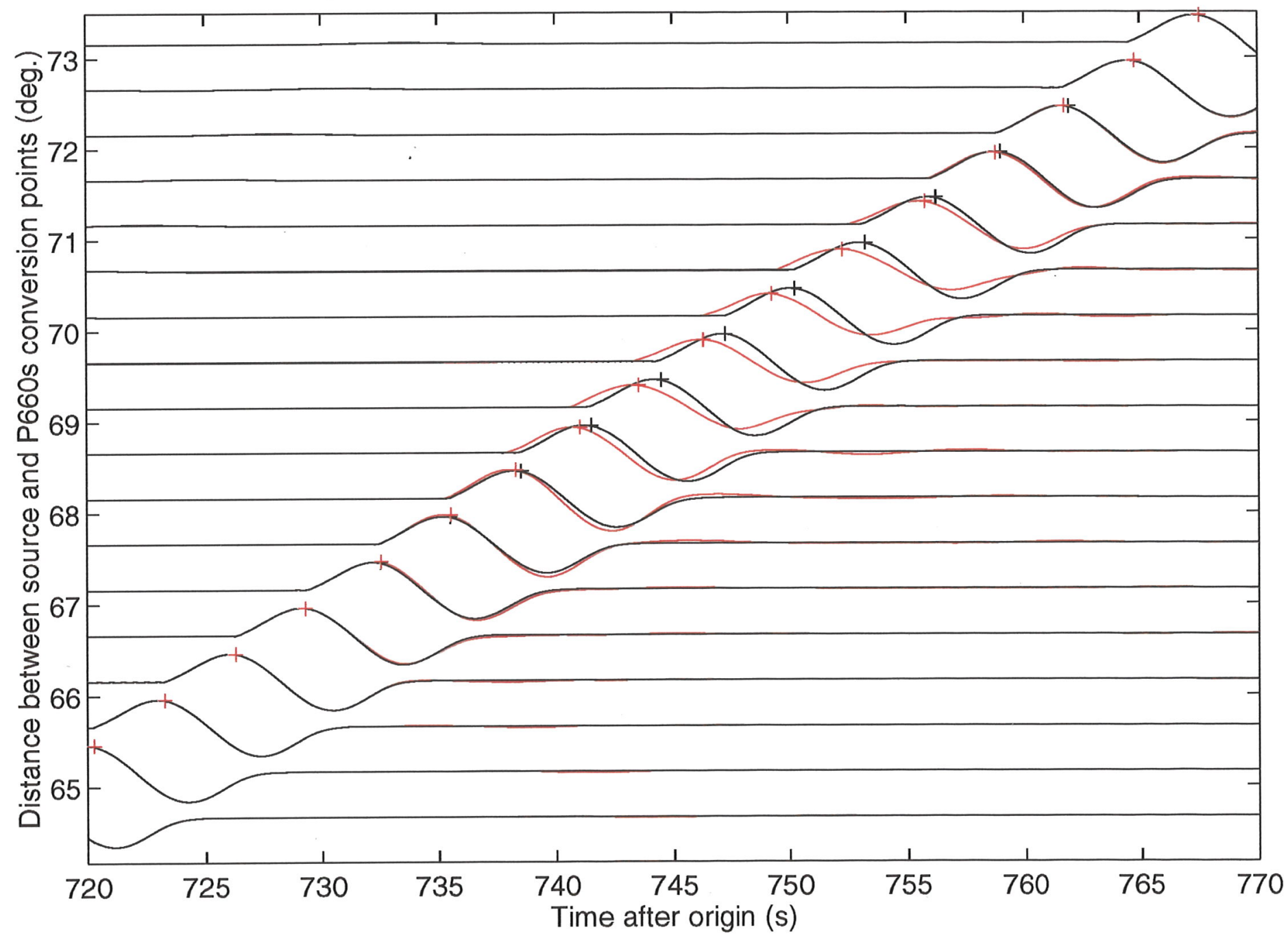


P660s - P410s (s, iasp91 - observed)

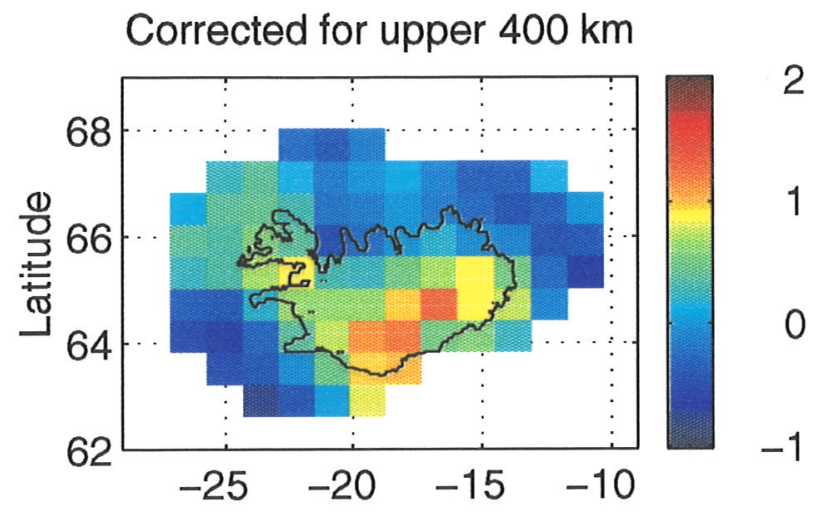

Figs 3 